\title{
IDEAS OF STUDENTS ON THE ATOMISTIC NATURE OF MATTER
}

\author{
CAMPOS, Angela Fernandes ${ }^{1 *}$; LUCENA, Michel Duarte Pergentino de ${ }^{2}$ \\ 1, Universidade Federal Rural de Pernambuco, Departamento de Química, Av. Dom Manoel de Medeiros, s/n, \\ Dois Irmãos, CEP 52171-900, Recife - PE, Brasil \\ (fone: +558133206370 ) \\ ${ }^{2}$ Colégio Motivo \\ Av. Paulo Santos, 96, Bairro Universitário \\ CEP: 550168- Caruaru - PE 33Brasil \\ (fone: +55813722.6011 ) \\ Autor correspondente: \\ e-mail: afernandescampos@gmail.com
}

Received 06 February 2018; received in revised form 13 March 2018; accepted 15 March 2018

\section{RESUMO}

O movimento das concepções alternativas que teve sua origem na década de 70 , até hoje tem sido de grande relevância no ensino de ciências e em particular no ensino de química, uma vez que podem ser ponto de partida para que professores repensem suas práticas pedagógicas. Nesse sentido, o movimento das concepções alternativas dialoga atualmente com tendências atuais de pesquisa no ensino de química, como resolução de problemas, experimentação no ensino de química, abordagem da ciência, tecnologia e sociedade, dentre outros. Portanto, o objetivo desse estudo foi analisar as ideias alternativas dos estudantes do ensino médio sobre a natureza atomística da matéria e se elas refletem os resultados obtidos em outros estudos sobre o tema. A metodologia consistiu na elaboração de duas questões abertas e posterior aplicação a 20 (vinte) estudantes do segundo ano do ensino médio da rede particular de ensino. Para análise, estabeleceram-se as categorias a priori "satisfatória", "parcialmente satisfatória", "não satisfatória", "não respondeu ou respostas evasivas". Os resultados se mostraram satisfatórios, com a maioria dos estudantes apresentando ideias prévias em concordância com as aceitas cientificamente. Além disso, não seguiram o mesmo padrão encontrado em outros estudos com alunos em diferentes níveis de ensino.

Palavras-chave: estudantes, natureza atomística da matéria, concepções alternativas.

\section{ABSTRACT}

The alternative concepts movement that emerged in the 1970s continues to be highly relevant in the teaching of sciences, particularly chemistry, given that it can be the starting point for teachers to revisit their pedagogic practices. In this respect, the alternative concepts movement currently discusses the tendencies of chemistry teaching research, such as problem-solving, experimental chemistry teaching, the scientific, technological and societal approach, among others. As such, the present study aimed to analyze the alternative ideas of high school students regarding the atomistic nature of matter and whether they reflect the results obtained in other research on the issue. The methodology involved preparing two open questions and their subsequent application to 20 second-year high school students at a private institution. Categories were established a priori as follows: satisfactory, partially satisfactory, not satisfactory or evasive answers. The findings were satisfactory, with most of the students presenting scientifically accepted ideas. Moreover, they did not exhibit the same pattern as in other investigations involving students from different teaching levels.

Keywords: ideas of students, atomistic, nature of matter, alternative conceptions. 


\section{INTRODUÇÃO}

Segundo Mortimer (1995), é bastante comum que os alunos dos ensinos fundamental e médio, apresentem concepções sobre a natureza atômica da matéria, bem diferentes das aceitas cientificamente. De acordo com o autor, na busca de compreender a natureza dessas concepções, bem como os padrões obedecidos por elas, foi realizada uma série de pesquisas em diferentes países nos quatro cantos do mundo que mostrou a universalidade das ideias alternativas que esses alunos apresentaram. Mortimer (1995) comenta que o entendimento da teoria atomística é muito importante para a compreensão da estrutura da matéria que está relacionada às propriedades microscópicas e macroscópicas e, portanto, se articula às transformações sofridas pela matéria e percebidas pelo estudante gerando ou reiterando as concepções alternativas. Em diálogo com essas ideias Pozo e Crespo (2009) ressaltam que a natureza e as propriedades da matéria e as mudanças que esta pode sofrer são conteúdos de química importantes e constituintes dos currículos dos ensinos fundamental e médio. Segundo eles, as noções sobre como é constituída a matéria são fundamentais para descrever e explicar sua estrutura nos diversos estados em que ela se apresenta, suas propriedades e todas as mudanças que possam ocorrer em sua estrutura, tanto físicas quanto químicas. No entanto, de acordo com Pozo e Crespo (2009), a maioria dos alunos utiliza muito pouco o modelo corpuscular em suas explicações quando precisam interpretar algum fenômeno químico cotidiano ou escolar. Quando o fazem utilizam as propriedades macroscópicas que são próximas do mundo real, em vez das microscópicas que necessitam do modelo corpuscular.

\section{São}

consideradas alternativas, interpretações errôneas ou

concepções equivocadas por parte dos alunos e que não se enquadram nos padrões atuais aceitos pela comunidade científica (BOO, 1998; ROBINSON, 1998). De acordo com Pozo et al (1991), elas podem originar-se de forma espontânea, transmitida ou induzida e analógica. A forma espontânea se dá devido ao senso comum e às experiências cotidianas em que os estudantes se incluem, e se baseiam na percepção dos fenômenos; quando são transmitidas ou induzidas, acontecem por meios culturais e sociais dos alunos antes mesmo da educação formal escolar, fazendo com que os mesmos cheguem à escola com ideias já formadas, construídas de modo informal e que nem sempre correspondem aos conceitos considerados verdadeiros, ou mesmo, aceitos pela comunidade científica. Já as de origem analógica compreendem as analogias desenvolvidas pelos alunos ou pelos professores durante a abordagem dos conceitos científicos. As pesquisas revelam ainda que tais características das concepções alternativas evoluem gradativamente com a idade e com a instrução do estudante, e que são encontradas ainda entre os alunos que já tenham passado pelo ensino formal. Internacionalmente muitos estudos sobre concepções alternativas dos estudantes em diferentes áreas do conhecimento foram desenvolvidos. No ensino de química, especificamente, destacam-se os trabalhos de Peterson (1989), Posada (1993,1999), Taber (1994) voltados para a estrutura interna da matéria e ligações químicas.

Pelo exposto, considerando a importância do movimento das concepções alternativas para a área de didática das ciências, em particular o ensino de química, e que o conhecimento das concepções alternativas dos estudantes pode ser ponto de partida para o professor refletir sobre o planejamento de atividades didáticopedagógicas, este estudo se propõe a analisar: as ideias alternativas dos estudantes do ensino médio sobre a natureza atomística da matéria e se as ideias apresentadas por eles refletem os resultados obtidos em outros estudos sobre o mesmo tema.

\section{MARCO TEÓRICO \\ Concepções alternativas: um caso particular dos conhecimentos prévios}

Segundo Teixeira (2010), os conhecimentos prévios podem ser considerados como produto das concepções de mundo da criança, formuladas a partir das interações que ela estabelece com o meio de forma sensorial, afetiva e cognitiva, ou, ainda, como resultado de crenças culturais e que, na grande maioria das vezes, são de difícil substituição por um novo conhecimento.

Há indivíduos, em particular os estudantes que possuem conhecimentos prévios relevantes, ou seja, conhecimentos sobre um dado conceito que expressa bem o que se espera do ponto de vista científico, por outro lado, há conhecimentos prévios dos estudantes 
que são um pouco desconexos com 0 conhecimento científico, nesses casos, dizemos que os estudantes apresentam ideias ou concepções alternativas ao conhecimento científico.

Pozo e Crespo (2009) mencionam que as concepções alternativas são o resultado de uma mente ou sistema cognitivo que tenta dar sentido a um mundo definido não apenas pelas relações entre os objetos físicos presentes no mundo, mas também pelas relações sociais que se estabelecem em torno desses objetos. Por isso, justificam eles, não é tão difícil livrar-se delas no ensino.

É importante ressaltar que o movimento das concepções alternativas que teve sua origem na década de 70, até hoje tem sido de grande relevância no ensino de ciências e em particular no ensino de química, no sentido que, o conhecimento das concepções alternativas dos estudantes podem ser um ponto de partida para que professores repensem suas práticas pedagógicas. Sob essa perspectiva inúmeras investigações surgiram e até os dias atuais ainda há estudos disponíveis na literatura no sentido de contribuir para explicitação das dificuldades de aprendizagem dos estudantes e promoção de estratégias didáticas que as levem em consideração a fim de contribuir para evolução das ideias deles do senso comum em direção a um modelo consensual científico.

Em nível nacional há algumas investigações em periódicos científicos na área de ensino de química que trata sobre as concepções alternativas dos estudantes em diferentes níveis de ensino. Sem a pretensão de esgotá-las aqui, destaca-se a seguir alguns estudos nessa direção: Mortimer (1995) traz uma pesquisa sobre as concepções atomistas dos estudantes do ensino fundamental e médio. Os resultados mostraram que os estudantes concebem a matéria como contínua, sem espaços vazios entre as partículas. Tal concepção proporciona muitos problemas para os estudantes compreenderem fenômenos que envolvem mudanças de estado físico, dilatação de gases e líquidos, dentre outros. Num outro fenômeno que envolveu o aquecimento de um gás dentro de um balão, os alunos atribuíram o aumento de volume a dilatação das próprias partículas. Segundo ele, esse tipo de concepção faz parte de uma ideia que se chama atomismo substancialista, que consiste em atribuir propriedades macroscópicas das substâncias, como dilatação, mudança de estado, aos átomos e moléculas. Segundo Mortimer (1995), essa ideia que se contrapõe ao conhecimento científico, os átomos ou moléculas dilatam-se quando uma substância é submetida ao aquecimento.

Com relação aos conceitos de elemento químico, substância simples, substância composto, misturas homogêneas e heterogêneas, Lacerda (2012) sistematiza alguns problemas de aprendizagem que são apresentados em diferentes estudos na literatura: substância simples considerada sinônimo de elemento químico; a associação errônea de substância a fase, trazendo problemas para entendimento de outros conceitos químicos como mistura homogênea e solução; misturas heterogêneas como leite e sangue consideradas homogêneas pelo fato dos alunos considerarem apenas o aspecto visual, a olho nu, dessas misturas.

No tocante à ligação química, Fernandes (2010) traz um resgaste dos principais problemas de aprendizagem desse conteúdo, descritos a seguir: os estudantes em diferentes níveis de ensino associam ligações fortes apenas a compostos iônicos; não conseguem estabelecer relações coerentes entre polaridade da ligação, moléculas polares e apolares e geometria molecular; não relacionam satisfatoriamente os três níveis de conhecimento químico representacional, macroscópico e microscópico; associam a formação de ligações fundamentalmente a obtenção de uma camada completa (regra do octeto).

Problemas de aprendizagem sobre reações químicas foram sistematizados num estudo realizado por Rosa e Schnetzler (1998). As concepções alternativas dos estudantes foram agrupadas nas seguintes categorias: (i)desaparecimento, ou seja, numa reação química, alguma(s) substância(s) desapare(cem); (ii) deslocamento, o processo químico ocorre porque uma substância se desloca de um espaço físico para outro; (iii)- modificação, sugere a mudança de estado físico da substância durante uma transformação (confusão entre processo físico e químico); (iv)- transmutação, numa reação química, as substâncias se transformam em energia e a energia se transforma em matéria.

Klein (2002) sistematiza em sua pesquisa algumas concepções alternativas dos estudantes referentes aos conceitos de calor e temperatura: (i)- o calor é geralmente associado a uma fonte 
ou a um estado; utiliza-se tanto o calor como a temperatura para designar um estado quente; (ii)- interpreta-se também a temperatura como a medida da mistura de calor e de frio dentro de um objeto; (iii)- a transmissão de calor através de uma barra metálica explica-se como a acumulação deste em uma parte da barra que vai propagando-se como um fluido ao outro extremo da mesma.

Os diversos problemas de aprendizagem dos conceitos apresentados de forma sucinta nos estudos supracitados são importantes e fazem parte do movimento das concepções alternativas. Por isso, se inserem nas tendências atuais de pesquisa no ensino de química, como, resolução de problemas ou situações-problema, experimentação no ensino de química, tecnologias da informação e comunicação no ensino de química, abordagem da ciência, tecnologia e sociedade, dentre outros, voltadas para proposição de estratégias didáticas. Nessa direção, vale destacar as pesquisas de Silva (2017), Simões Neto (2013), Lacerda (2012), Veríssimo (2011) que envolvem estratégias didáticas no ensino de química pautadas na resolução de situações-problema e consideram as dificuldades de aprendizagem de conteúdos químicos retratadas nos estudos sobre concepções alternativas.

\section{METODOLOGIA}

A seguir são descritas as atividades e ações realizadas para atender aos objetivos desse estudo.

\section{Etapa 1: Elaboração de um questionário}

Um questionário com duas questões abertas foi construído tendo como referência o estudo realizado por Mortimer (1995) que envolveu as concepções atomistas dos estudantes do ensino fundamental. $O$ artigo de Mortimer (1995) discute as concepções alternativas deles sobre a matéria e nesse sentido verifica a atribuição de propriedades macroscópicas aos átomos por eles e a dificuldade deles em aceitar a existência de espaços vazios entre as partículas de matéria. Dentre as questões propostas por Mortimer aos estudantes, selecionamos duas delas para aplicação aos alunos do primeiro ano do ensino médio de uma escola privada da região metropolitana de Recife-PE, que são mostradas a seguir:

QUESTÃO 01. Considere a figura mostrada a seguir. Explique como está o ar antes e depois da compressão e o fato de podermos comprimilo. Mostre através de desenho as partículas do ar antes e após a compressão.

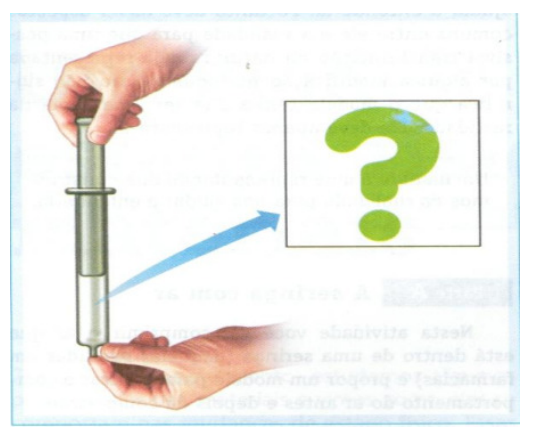

Figura 1. Seringa antes de o ar em seu interior ser comprimido (Mortimer, 2002).

QUESTÃO 2. Considere a figura mostrada a seguir. O que acontece com o ar dentro do tubo, antes e após o aquecimento? Mostre através de desenho as partículas do ar antes e após o aquecimento do tubo.



Figura 2. a) Frasco de Kitasato antes da experiência; b) Frasco de Kitasato depois da experiência (Mortimer, 2002).

Nas duas questões foi solicitado aos estudantes que desenhassem modelos para explicar os fenômenos. Além da resposta escrita do estudante a representação que ele faz do fenômeno auxilia na identificação pelo pesquisador dos modelos elaborados individualmente pelos estudantes.

\section{Etapa 2: Aplicação do questionário}

O questionário foi aplicado a 20 (vinte) estudantes, de faixa etária entre 15-17 anos, do segundo ano do ensino médio de uma escola particular da região metropolitana de Recife. 
Teve a duração de aplicação 1 (uma) hora. Os estudantes foram informados no momento da aplicação do questionário que respondessem individualmente e que dúvidas seriam esclarecidas apenas referente aos enunciados das questões. Ainda, eles não podiam consultar os colegas durante a construção de suas respostas.

\section{Etapa 3: Análise das respostas dos estudantes ao questionário.}

Para análise das respostas dos estudantes ao questionário foram estabelecidas categorias comumente utilizadas na metodologia qualitativa de pesquisa científica (LUDKE, 1986). As categorias, a priori, nesse caso, tendo como referência, mais uma vez, o estudo de Mortimer (1995). Dessa forma, para as duas questões as categorias são descritas a seguir nas tabelas $1 \mathrm{e}$ 2:

\section{RESULTADOS E DISCUSSÃO:}

$\mathrm{Na}$ questão 1, apenas 2 alunos responderam dentro da categoria NS, ou seja, não satisfatória ou que revelou uma concepção alternativa, e, apenas um aluno não respondeu à questão. A fim de realizar uma melhor análise, a seguir serão apresentadas as respostas satisfatória e parcialmente satisfatória de alguns estudantes para a questão citada.

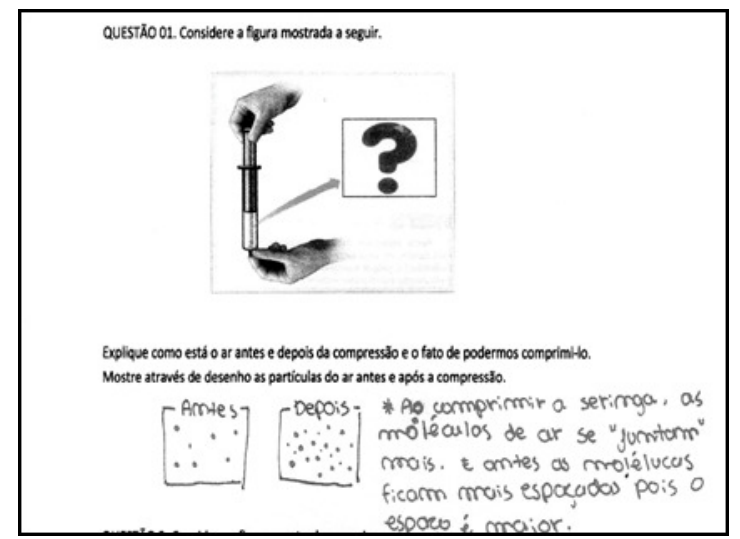

Figura 3. Resposta do aluno 9 à questão 1.

Pode-se observar na figura 3 que 0 aluno 9 comenta que antes da compressão da seringa o ar se "junta" mais e antes as moléculas eram mais espaçadas. $O$ desenho ilustra bem a representação do aluno sobre o que acontece com o ar antes e após a compressão. Observe que a ideia expressa pelo aluno de espaço vazio entre as moléculas de ar antes e após a compressão da seringa se mantém, o que demonstra que 0 aluno não apresenta a concepção alternativa de continuidade da matéria, conforme foi apresentado por vários estudantes no estudo de Mortimer (1995).

A figura 4 ilustra uma resposta parcialmente satisfatória dada pelo aluno 6 . Pode-se observar que ele responde como esperado, comenta que após a compressão da seringa, diminui o espaço dentro do objeto, e por isso, tem um menor espaço entre as moléculas. Apesar disso, o aluno 6 não mostra o desenho das partículas do ar antes e após a compressão.

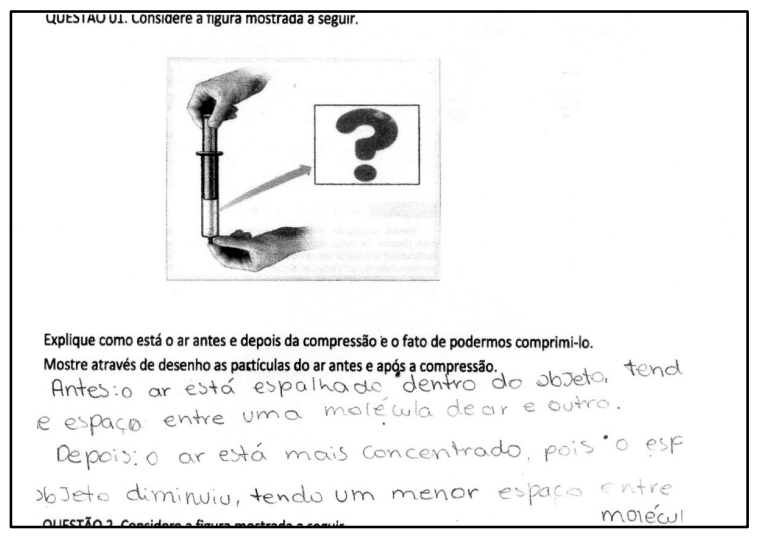

Figura 4. Resposta do aluno 6 à questão 1.

O aluno 1 tem um comportamento inverso, ele faz uma boa representação do fenômeno, mostrando espaços vazios entre as partículas do ar antes e após a compressão, porém sua resposta não menciona a diminuição dos espaços entre as partículas de ar após a compressão da seringa, por isso, sua resposta foi considerada parcialmente satisfatória.

Ainda, na questão 1 apenas 2 alunos apresentaram a concepção alternativa sobre continuidade da matéria. Isso ficou explícito quando eles representaram as partículas de ar após a compressão da seringa. O aluno 8 , figura 5, inclusive comentou: "....depois da compressão as moléculas estão todas juntas, fazendo com que a força aplicada seja cada vez maior. A resposta dá a ideia de que quanto maior a força aplicada, mais ainda as moléculas de ar ficarão juntas, o aluno também não considera que há um limite de espaço entre as moléculas devido às forças intermoleculares. Segundo Mortimer (1995) a idéia que 'a natureza abomina o 'vazio' é uma característica presente nas explicações dos estudantes para diferentes fenômenos. Eles usam esse mesmo tipo de concepção para 
explicar, por exemplo, por que uma caixa de papelão vazia colapsa quando suga-se 0 ar em seu interior com o auxílio de um canudo.



Figura 5. Resposta do aluno 8 à questão 1.

Pelo exposto, pode-se inferir que os estudantes do primeiro ano do ensino médio, sujeitos da pesquisa tiveram uma boa representação do fenômeno, uma vez que 7 deles apresentaram respostas satisfatórias. Mais da metade dos estudantes realizaram uma representação do fenômeno ou responderam como esperado, no entanto, não conseguiram atender em sua plenitude ao que a questão propunha. Curiosamente, apenas 2 alunos apresentaram a concepção alternativa que diz respeito à continuidade da matéria bastante discutida por Mortimer (1995) em seu estudo. Pode-se afirmar que os alunos investigados não apresentaram em sua maioria essa concepção alternativa, o que faz com que esses alunos apresentem ideias prévias importantes para aprendizagem de conteúdos como mudanças de estados físicos, compressão e dilatação de gases e líquidos, dentre outros.

Para a questão 2, a maior quantidade de alunos, 09 alunos responderam de forma PS, representando $45 \%$ do total, enquanto 06 alunos responderam de maneira S. Apenas 3 alunos responderam dentro da categoria NS, ou seja, que revelou uma concepção alternativa, e, 2 alunos não responderam à questão.

Como podemos observar na figura 6 , o aluno 13 cita uma possível "agitação" das moléculas mediante o aquecimento. A ilustração do estudante mostra a maior parte do ar provocando um aumento de volume no balão. Segundo ele, a agitação do ar devido ao aquecimento é responsável pelo deslocamento do ar. Percebe-se que o aluno 13 consegue fazer a relação do calor à energia cinética, nesse sentido para descrever o movimento das partículas do ar devido ao aquecimento ele utiliza o termo agitação, por isso, sua resposta foi considerada satisfatória.

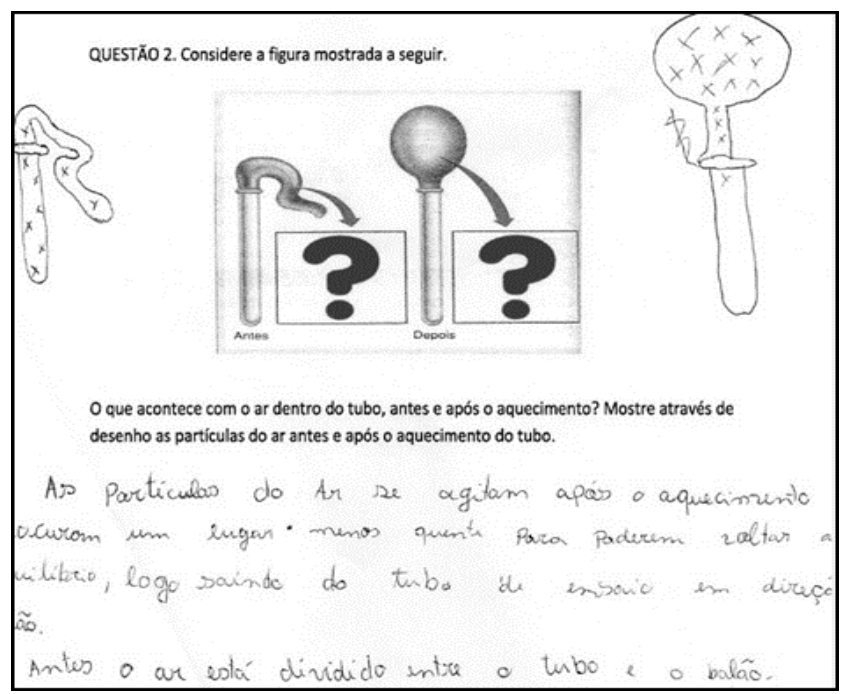

Figura 6. Resposta do aluno 13 a questão 02.

Outra resposta satisfatória foi apresentada pelo aluno 18, figura 7 . Ele mostra que as partículas ocupam todo o ambiente após o aquecimento além de atribuir ao calor a causa dessa 'migração'. O aluno 18 também indica a noção de agitação que, nesse caso, pode ser atribuído ao movimento das partículas ocasionado pelo aumento da energia cinética e que tal fenômeno foi atribuído ao calor. A representação gráfica da figura 7 também demonstra a ideia de descontinuidade da matéria, pois mesmo com o aquecimento do ar ele considera a possibilidade de espaços vazios, mesmo as partículas ocupando todo o ambiente, o que é compatível com o conceito científico de expansão gasosa.

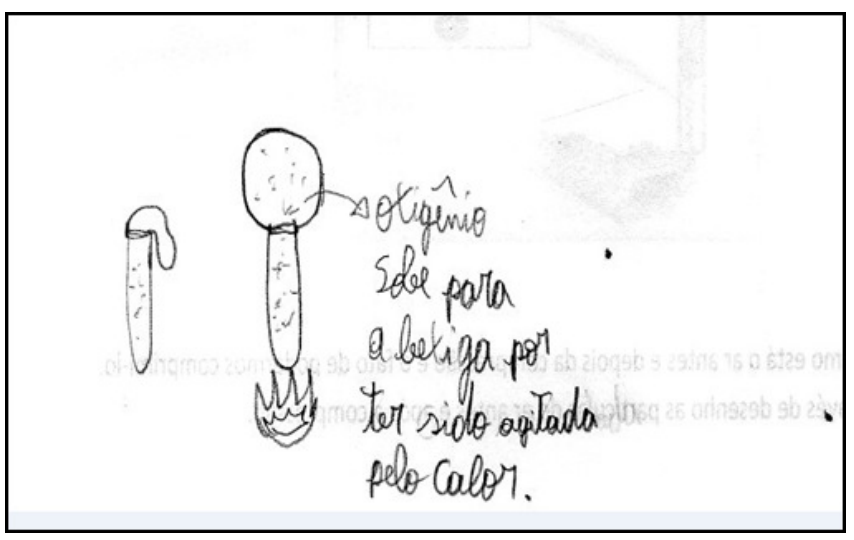

Figura 7. Resposta do aluno 18 a questão 02. 
Apenas 3 alunos apresentaram a concepção alternativa de atribuir a expansão do gás pelo aquecimento a dilatação das partículas do ar. Segundo Mortimer (1995) o conceito da dilatação das partículas é muito comum nos modelos atomistas intuitivos elaborados pelos estudantes. Porém, nesse caso, poucos alunos apresentaram esse tipo de concepção o que demonstra que os alunos apresentam concepções prévias relevantes sobre esses fenômenos.

\section{CONCLUSÕES:}

O fato de uma boa parte dos alunos que participou da investigação ter apresentado poucas concepções alternativas sobre a natureza atômica da matéria é relevante uma vez que para compreensão de vários fenômenos em química é necessário ideias prévias em conformidade com os modelos científicos para a aprendizagem dos estudantes de assuntos mais avançados como os modelos atômicos, ligações químicas, dentre outros. No entanto, o fato de alunos, ainda que poucos, terem apresentado concepções alternativas sobre a natureza atomística da matéria reitera a necessidade de pensar em estratégias didáticas que as levem em consideração, a fim de minimizar os problemas de aprendizagem sobre esse tema.

\section{AGRADECIMENTOS:}

Aos alunos partícipes da pesquisa; a direção e gestão da escola e a UFRPE.

\section{REFERÊNCIAS:}

1. Boo, H. K. Students' understandings of chemical bonds and the energetics of chemical reactions. Journal of Research in Science Teaching, 1998, 5, 35, 569.

2. Fernandes, L. dos.; Campos, A. F. Concepções alternativas dos estudantes sobre ligação química. Experiências em Ensino de Ciências, 2010, 5, 3, 19.

3. Klein, J. F. K.; Peduzzi, S. S. Um estudo a respeito das concepções alternativas sobre calor e temperatura. Revista Brasileira de Pesquisa em Educação em Ciências, 2002, 2, 33, 84.

4. Lacerda, C. de C., \& Campos, A. F., \& Marcelino-Jr, C. de A. C. M. Abordagem dos conceitos mistura, substância simples, substância composta e elemento químico numa perspectiva de ensino por situação-problema. Química Nova na Escola, 2012, 34, 2, 75.

5. Lüdke, M. e André, M. E. D. A. Pesquisa em educação: abordagens qualitativas. São Paulo: Editora EPU, 1986.

6. Mortimer, E. F. C. Concepções atomistas dos estudantes. Química Nova na Escola, 1995, n.1, 23.

7. Peterson, R.F. e Treagust, D.F. Grade-12 students' misconceptions of covalent bonding and structure. Journal of Chemical Education, 1989, 66, 459.

8. Posada, J. M. Concepciones de los alumnos de 15-18 años sobre la estructura interna de la materia en el estado sólido. Enseñanza de las Ciencias, 1993, 11, 12.

9. Posada, J. M. Concepciones de los alumnos sobre el enlace químico antes, durante y después de la enseñanza formal. Problemas de aprendizaje. Enseñanza de las Ciencias, 1999, 17, 227.

10. Pozo, J. A.; Sanz, A.; Crespo Gómez, M. A.; Limón, M. Las ideas de los alumnos sobre la ciencia: un interretación desde la psicología cognitiva. Enseñanza de las Ciências, 1991, 9, 1, 83.

11. Pozo, J. A.; Crespo Gómez, M. A.; A aprendizagem e o ensino de ciências: do conhecimento cotidiano ao conhecimento científico. Porto Alegre: Editora Artmed, 2009.

12. Robinson, W. R. An alternative framework for chemical bonding. Journal of Chemical Education, 1998, 9, 75, 1074.

13. Rosa, M. I. P; Schnetzler, R. Sobre a importância do conceito Transformação Química no processo de aquisição do Conhecimento Químico. Química Nova na Escola, 1998, 8, 2, 31.

14. Silva, F. C. V.; Campos, A. F.; Almeida, M. A. V. Situação-Problema sobre Radioterapia no Ensino Superior de Química: Contextos de uma Investigação. Experiências em Ensino de Ciências, 2017, 12, 1, 14.

15. Simões Neto, J. E., \& Campos, A. F., \& Marcelino-Jr, C. A. C. El uso de situaciones-Problema para la enseñanza superior de isomeria en la química inorgánica. Avances en Ciencias e Ingeniería, 2013, 4, 2, 61.

16. Taber, K.S. Misunderstanding the ionic 
bond. Education in Chemistry, 1994, 31, 4,100 .

17. Teixeira, F. M.; Sobral, A. C. M B. Como novos conhecimentos podem ser construídos a partir dos conhecimentos prévios: um estudo de caso. Ciência \& Educação, 2010, 16, 3, 667.

18. Veríssimo, V. B.; Campos, A. F. Abordagem das propriedades coligativas das soluções numa perspectiva de ensino por situação-problema. Revista Brasileira de Ensino de Ciência e Tecnologia, 2011, 4, 3, 101. 
Tabela 1. Categorias a priori para a questão 1.

Categorias

Satisfatória (S)

Satisfatória (PS)

Não Satisfatória

(NS) ou que reflete

uma concepção

alternativa

Não Respondeu

(NR) ou respostas

evasivas (RE)

\section{Descrição}

há espaços vazios entre as partículas de matérias, ou seja, a matéria é descontínua.

o estudante faz a representação como esperado por meio de um desenho, mas não responde, ou responde a questão como esperado porém não faz a representação. Tal categoria é considerada, pois, no estudo de Mortimer (1995), verificou-se que alguns estudantes apesar de representar as partículas do ar com espaços vazios entre elas, suas respostas insistiam num modelo contínuo para melhor representar o ar. não há espaços vazios entre as partículas, entre elas existem outras partículas.

são as respostas dos estudantes que não se enquadraram nas categorias satisfatória, parcialmente satisfatória ou não responderam
Tabela 2. Categorias a priori para a questão 2.

\section{Categorias}

\section{Descrição}

\begin{tabular}{ll}
\hline & $\begin{array}{l}\text { De acordo com o modelo científico clássico: o aumento do } \\
\text { volume de um gás submetido ao aquecimento é } \\
\text { conseqüência do aumento de energia cinética média das } \\
\text { moléculas do gás, o que aumenta a distância média entre } \\
\text { elas. }\end{array}$ \\
\hline Parcialmente Satisfatória (PS) & $\begin{array}{l}\text { o estudante faz a representação como esperado por meio } \\
\text { de um desenho, mas, não responde ou responde a } \\
\text { questão como esperado porém não faz a representação. }\end{array}$ \\
\hline Não Satisfatória (NS) ou que reflete & $\begin{array}{l}\text { o aumento do volume de um gás submetido ao } \\
\text { aquecimento é conseqüência da dilatação das próprias } \\
\text { partículas. }\end{array}$ \\
\hline uma concepção alternativa & $\begin{array}{l}\text { são as respostas dos estudantes que não se enquadraram } \\
\text { nas categorias satisfatória, parcialmente satisfatória ou } \\
\text { não responderam. }\end{array}$ \\
\hline Não Respondeu (NR) ou respostas \\
evasivas (RE)
\end{tabular}
evasivas (RE) não responderam. 